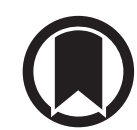

CrossMark

\title{
Changing trends in age-adjusted pulmonary fibrosis mortality in the USA: a joinpoint regression analysis
}

\author{
To the Editor:
}

The mortality attributed to pulmonary fibrosis has been shown to steadily increase from 1979 to 2010 in the USA and from 2001 to 2013 across the European Union [1-5]. However, it is unknown if this trend continues in the USA in recent years. By evaluating the National Center for Health Statistics underlying cause of death database, the current study updates previous analyses by using a joinpoint regression model for determining changes in the trend of pulmonary fibrosis deaths in the USA, from 1999 to 2017.

Data were obtained from the Centers for Disease Control and Prevention's Wide-ranging Online Data for Epidemiologic Research [6]. This programme contains data on death certificates for US residents. Each death certificate contains a single underlying cause of death, up to 20 additional multiple contributing causes, and demographic data. The primary aim was to describe temporal trends in death rates attributable to pulmonary fibrosis (International Classification of Diseases, 10th revision (ICD-10), code J84.1) as the underlying cause of death.

Age-adjusted mortality rates were computed by the direct method to the projected year 2000 US population. Trends in the mortality rate from pulmonary fibrosis were calculated stratified by age, sex, race, and geographic area of residence.

Among subjects in whom pulmonary fibrosis is the underlying cause of death, the coexistence of comorbid conditions or contributing causes of death, such as infections (e.g. possibly triggering acute exacerbations of pulmonary fibrosis), may influence the clinical course and survival of pulmonary fibrosis [7]. Therefore, to gain understanding on the potential impact of contributing causes of death on pulmonary fibrosis mortality secular trends, the yearly estimates of pneumonia and influenza (J09-J18), septicaemia (A40-A41), heart failure (I50), ischaemic heart disease (I20-I25), pulmonary heart disease (I26-I28), chronic obstructive pulmonary disease (J40-J44), diabetes (E10-E14), cerebrovascular disease (I60-I69) and lung cancer (C34) were examined as they are among the 10 leading causes of death in the USA [8].

The joinpoint software (version 4.6) was used to compute the years in the study period at which change in mortality occurred and was statistically significantly different (i.e. increased or decreased trend) or remained stable, the annual percentage change, and the average annual percent change from 1999 to 2017. For each annual percent change, 95\% confidence intervals were calculated based on a t-distribution. Allowing as few as two observed time points, in the beginning, ending, and middle line segments (including the joinpoints), a maximum of two joinpoints were searched for using the Grid search algorithm and the Bayesian Information Criterion test and an overall alpha level set at 0.05 [9].

From 1999 to 2017, pulmonary fibrosis was recorded as the underlying cause of death in 230900 decedents in the USA. During this period, the age-adjusted mortality rate increased by an average of $0.7 \%$ per year. Overall, age-adjusted mortality rates were highest in men, in non-Hispanic white subjects, and the Midwestern USA. Also, crude rates increased with age (table 1).

@ERSpublications

Pulmonary fibrosis mortality rate increased from 1999 until reaching an inflection point in 2004. Subsequently, mortality rates decreased from 2004 to 2017 and concurred with significant downward trends in cardiovascular, pneumonia and influenza mortality. http://bit.ly/2KTFWPE

Cite this article as: Fernández Pérez ER. Changing trends in age-adjusted pulmonary fibrosis mortality in the USA: a joinpoint regression analysis. Eur Respir J 2019; 54: 1900364 [https://doi.org/10.1183/ 13993003.00364-2019]. 
TABLE 1 Age-adjusted and trends in annual percent change in mortality rates due to pulmonary fibrosis as the underlying cause of death by demographic characteristic in the USA, 1999-2017

\begin{tabular}{|c|c|c|c|c|c|}
\hline \multirow[t]{2}{*}{ Variable } & \multicolumn{2}{|c|}{ Pulmonary fibrosis mortality } & \multicolumn{2}{|c|}{ Annual percent change $(95 \% \mathrm{CI})^{\#}$} & \multirow{2}{*}{$\begin{array}{c}\text { Average annual percent } \\
\text { change }(95 \% \mathrm{CI}){ }^{\pi} \\
1999-2017\end{array}$} \\
\hline & Deaths $\mathrm{n}(\%)$ & $\begin{array}{l}\text { Age-adjusted rate per } 1000000 \\
\qquad(95 \% \mathrm{Cl})\end{array}$ & Trend 1 & Trend 2 & \\
\hline Overall & $230900(100)$ & 37.9 (37.7 to 38.1$)$ & $1999-2004 ; 4.0$ (2.3 to 5.8$)$ & $2004-2017 ;-0.6(-1.0$ to -0.3$)$ & $0.7(0.2$ to 1.1$)$ \\
\hline \multicolumn{6}{|c|}{ 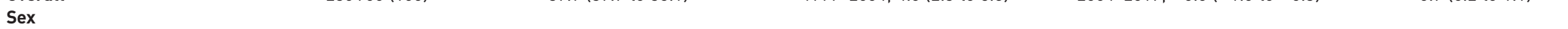 } \\
\hline Men & $123387(53.4)$ & 49.6 (49.4 to 49.9$)$ & $1999-2005 ; 3.0$ (1.1 to 5.0$)$ & $2005-2017 ;-0.5(-1.1$ to 0.1$)$ & $0.6(0.0$ to 1.3$)$ \\
\hline Women & $107513(46.6)$ & $29.8(29.6$ to 29.9$)$ & $1999-2004 ; 4.1$ (2.1 to 6.2 ) & $2004-2017 ;-1.1(-1.5$ to -0.7$)$ & $0.3(-0.2$ to 0.9$)$ \\
\hline \multicolumn{6}{|l|}{ Race } \\
\hline White, non-Hispanic & $194633(84.2)$ & $39.4(39.2$ to 39.6$)$ & $1999-2004 ; 4.2$ (2.5 to 6.0 ) & $2004-2017 ;-0.4(-0.7$ to 0$)$ & $0.9(0.4$ to 1.4$)$ \\
\hline Men & $105659(45.7)$ & 52.2 (51.9 to 52.5 ) & $1999-2004 ; 3.7$ (2.0 to 5.5 ) & $2004-2017 ;-0.1(-0.5$ to 0.2$)$ & $0.9(0.4$ to 1.4$)$ \\
\hline Women & $88974(38.5)$ & $30.4(30.2$ to 30.6$)$ & $1999-2004 ; 4.5$ (2.4 to 6.8$)$ & $1999-2017 ;-0.9(-1.4$ to -0.5$)$ & $0.6(-0.1$ to 1.2$)$ \\
\hline Black, non-Hispanic & $11685(5.1)$ & $20.9(20.5$ to 21.3$)$ & $1999-2005 ; 1.8(-1.4$ to 5.1$)$ & $2005-2017 ;-2.3(-3.3$ to -1.2$)$ & $-0.9(-2.1$ to 0.2$)$ \\
\hline Men & $5388(2.3)$ & 25.1 (24.4 to 25.8 ) & $1999-2005 ; 3.5(-0.2$ to 7.4$)$ & $2005-2017 ;-2.5(-3.6$ to -1.3$)$ & $-0.5(-1.8$ to 0.8$)$ \\
\hline Women & $6297(2.7)$ & 18.8 (18.3 to 19.2$)$ & & & $-1.6(-2.2$ to -0.9$)$ \\
\hline Hispanic & $17430(7.5)$ & $42.9(42.3$ to 43.6$)$ & & & $-0.5(-1.1$ to 0.1$)$ \\
\hline Men & $8624(3.7)$ & $50.2(49.1$ to 51.4$)$ & & & $-0.3(-0.9$ to 0.4$)$ \\
\hline Women & 8806 (3.8) & 37.7 (36.9 to 38.5 ) & $1999-2005 ; 3.2$ (-0.7 to 7.2 ) & $2005-2017 ;-1.7(-2.7$ to -0.6$)$ & $-0.1(-1.4$ to 1.3$)$ \\
\hline \multicolumn{6}{|l|}{ Census region } \\
\hline Northeast & $38839(16.8)$ & 31.8 (31.5 to 32.1$)$ & $1999-2005 ; 4.2(1.9$ to 6.5$)$ & $2005-2017 ;-0.2(-0.9$ to -0.7$)$ & $1.2(0.4$ to 2.0$)$ \\
\hline Midwest & $57746(25.0)$ & $41.41(41.1$ to 41.7$)$ & $1999-2005 ; 4.1$ (1.9 to 6.4$)$ & $2005-2017 ;-0.9(-1.5$ to -0.2$)$ & $0.8(0.0$ to 1.5$)$ \\
\hline South & 86705 (37.5) & 39.47 (39.2 to 39.7 ) & $1999-2004 ; 3.2(1.3$ to 5.1$)$ & $2004-2017 ;-0.4(-0.8$ to 0.0$)$ & $0.6(0.0$ to 1.1$)$ \\
\hline West & $47610(20.6)$ & 37.17 (36.8 to 37.5$)$ & $1999-2004 ; 2.7(1.0$ to 4.3$)$ & $2004-2017 ;-1.6(-2.1$ to -1.1$)$ & $-0.2(-0.8$ to 0.4$)$ \\
\hline \multicolumn{6}{|l|}{ Age groups $^{+}$} \\
\hline $35-44$ years & $1607(0.7)$ & $1.9(1.9$ to 2.1$)$ & & & $-3.5(-4.9$ to -2.2$)$ \\
\hline $45-54$ years & $6655(2.9)$ & $8.3(8.1$ to 8.5$)$ & & & $-2.5(-3.2$ to -1.8$)$ \\
\hline $55-64$ years & $20291(8.8)$ & 31.7 (31.3 to 32.2 ) & & & $-1.8(-2.3$ to -1.4$)$ \\
\hline $65-74$ years & $51776(22.4)$ & 124.5 (123.4 to 125.5$)$ & $1999-2004 ; 3.1(1.0$ to 5.1$)$ & $2004-2017 ;-1.9(-2.3$ to -1.5$)$ & $-0.6(-1.1$ to 0.0$)$ \\
\hline $75-84$ years & 87318 (37.8) & $348.3(346.0$ to 350.6$)$ & $1999-2006 ; 3.6$ (1.9 to 5.4$)$ & $2006-2017 ;-0.6$ (-1.4 to 0.2 ) & $1.0(0.2$ to 1.8$)$ \\
\hline$\geqslant 85$ years & $62443(27.1)$ & 626.3 (621.4 to 631.2 ) & $1999-2005 ; 4.6$ (2.8 to 6.4$)$ & $2005-2017 ; 0.7$ (0.3 to 1.2 ) & $2.0(1.4$ to 2.6$)$ \\
\hline \multicolumn{6}{|l|}{ Contributing causes of death ${ }^{\S}$} \\
\hline Pneumonia and influenza & $29162(12.6)$ & $4.8(4.7$ to 4.8$)$ & $1999-2004 ; 6.9(-0.6$ to 15$)$ & $2004-2017 ;-3.7(-4.3$ to -3$)$ & $-1.2(-3.6$ to 1.2$)$ \\
\hline Ischaemic heart disease & $25871(11.2)$ & $4.3(4.2$ to 4.3$)$ & $1999-2007 ; 1.9(-0.8$ to 4.7$)$ & $2007-2017 ;-2.8(-4.8$ to -0.8$)$ & $-0.7(-2.2$ to 0.8$)$ \\
\hline Heart failure & $24987(10.8)$ & $4.1(4.0$ to 4.1$)$ & & & $0.5(-0.3$ to 1.3$)$ \\
\hline COPD & $23280(10.1)$ & 3.8 (3.8 to 3.9 ) & & & $1.1(-0.4$ to 2.6$)$ \\
\hline Diabetes & $16030(6.9)$ & $2.6(2.6$ to 2.7$)$ & & & $0.5(-0.3$ to 1.3$)$ \\
\hline Pulmonary heart disease & $15550(6.7)$ & 2.5 (2.5 to 2.6$)$ & & & $1.3(0.5$ to 2.1$)$ \\
\hline Septicaemia & $5559(2.4)$ & $0.9(0.9$ to 0.9$)$ & $1999-2008 ; 5.0$ (2.6 to 7.4$)$ & $2008-2017 ;-0.3(-2.0$ to 1.5$)$ & $2.6(-0.1$ to 5.4$)$ \\
\hline Cerebrovascular disease & $3734(1.6)$ & $0.6(0.6$ to 0.6$)$ & & & $-2.0(-2.8$ to -1.1$)$ \\
\hline Lung cancer & $1792(0.8)$ & $0.3(0.3$ to 0.3$)$ & & & $-1.1(-2.4$ to 0.3$)$ \\
\hline
\end{tabular}

The annual percent change or average annual percent change is significant if confidence intervals do not cross zero ( $p<0.05$ ). COPD: chronic obstructive pulmonary disease. \#: years included are linear segments that have different slopes and are connected at the time point where a change in trend occurs (referred to as joinpoint). For example, for the overall variable, one joinpoint was identified in 2004 and two-line segments or time periods (trend 1: 1999-2004, and trend 2: 2004-2017). If data are not shown, it is because there are no joinpoints and regression analysis of all time points each year shows no significant departures from a linear trend. ": the average annual percent change is a weighted average of the annual percent changes, with the weights equal to the length of the joinpoint segments. ${ }^{+}$: these numbers represent crude rates and confidence intervals. ${ }^{\S}$ : the National Center for Health Statistics multiple cause of death data include conditions that are important contributors to death (i.e. the disease or injury that contributed to the fatal outcome) but were not reported as the underlying cause (i.e. the disease or injury that initiated the chain of morbid events leading directly to death). 
During the study period, two segmented trends were identified by the joinpoint analyses (1999-2004 and 2004-2017). The age-adjusted mortality rate increased from 1999 (32.9 per 1000000 population) until reaching a peak in 2004 (42.3 per 1000000 population; annual percent change $4.0 \%$ ). Thereafter, the age-adjusted mortality rate for pulmonary fibrosis decreased from 42.3 per 1000000 population in 2004 to 36.4 per 1000000 population in 2017, with an annual percentage reduction of $0.6 \%$. Age-adjusted mortality trends for pulmonary fibrosis as multiple cause of death (i.e. pulmonary fibrosis-related death) had a trajectory analogous to the trends when pulmonary fibrosis was listed as the underlying cause of death. One joinpoint was identified at 2003. From 1999 to 2003 the annual percent change was 2.2\% (95\% CI $1.2 \%$ to $3.2 \%$ ) and from 2003 to 2017 the annual percent change was $-0.8 \%$ ( $95 \%$ CI $-0.9 \%$ to $-0.7 \%$ ); average annual percent change $-0.1 \%(95 \% \mathrm{CI}-0.3 \%$ to $0.1 \%)$.

Annual percent change trends in age-adjusted mortality from pulmonary fibrosis stratified by sex, race and geographic region were similar to overall trends, with significant increases or stable changed from 1999 that lasted 5 to 6 years before either levelling off or significantly decreasing (table 1). Within subgroups defined by race and sex, while white men had an increase in the age-adjusted mortality average annual percent change, black women experienced a decreased trend from 1999 to 2017. Stable trends were observed among other sex/racial groups (table 1; average annual percent change). All US geographic regions had stable trends except the Northeastern USA, which experienced significant increases in mortality over the study period. A mortality reduction was observed in decedents under age 65 years while significant increases in mortality rates were observed among adults $\geqslant 85$ years old.

Pneumonia and influenza infection were the most prevalent contributing causes of death in subjects with pulmonary fibrosis. Notably, during the study period, compared to June through November, the average number of deaths among subjects with pulmonary fibrosis was higher from December through May, the influenza season (951, 95\% CI 928 to 975 versus 1074, 95\% CI 1045 to 1102). From 1999 to 2017, stable average annual percentage trends were observed in all but two (pulmonary heart disease, average annual increase of $1.3 \%, 95 \%$ CI $0.5 \%$ to $2.1 \%$; cerebrovascular disease, average annual decrease of $-2.0 \%, 95 \%$ CI $-2.8 \%$ to $-1.1 \%$ ) of the 10 contributing causes of death (table 1 ).

Prior studies have indicated a rise in pulmonary fibrosis related mortality in the USA since the 1970s [2-4]. Although the increase in the age-adjusted mortality rate in pulmonary fibrosis of $4 \%$ points per year during 1999-2004 and in pulmonary fibrosis deaths in older adults notably outnumbering younger age groups mirrors prior epidemiological findings, the age-adjusted mortality has subsequently demonstrated a decline by $0.6 \%$ annually from 2004 to 2017 . The observed recent slight decline in overall death rates may have several different explanations. First, it is possible that improved recognition and awareness of interstitial lung diseases other than idiopathic pulmonary fibrosis has been increasing. Second, the decrease in age-adjusted mortality in pulmonary fibrosis concurred with significant downward trends in pneumonia and influenza mortality rates over the same interval (decreasing 3.7\% per year from 2004 to 2017). These estimates of averted disease burden may be attributed to improvements in pneumococcal and seasonal influenza vaccination or targeted prophylaxis nationally [10]. Similarly, the decrease in ischaemic heart disease (2004-2017) and cerebrovascular complications (1999-2017) attributed to improvements in control of hypertension, hyperlipidaemia, and smoking cessation may have also contributed to the decreasing trend in pulmonary fibrosis mortality since $2004[11,12]$. Lastly, it is unclear if enhanced disease awareness, access to specialised care and antifibrotic therapy, improvement in comorbid disease management, supportive care and lung transplant survival could have contributed to the decelerating mortality rates in recent years.

This study is limited by potential misclassification of death certificate codes, which may influence the interpretation of our findings. Notwithstanding the reported inaccuracies in death certificate data, the overall declining trends from 2004 to 2017 seem unlikely to be solely explained by yearly coding errors and underreporting.

The 2004 joinpoint marks a new trend (2004-2017) that differs significantly from 1999 to 2004 . It is possible that this 2004 joinpoint represents differences in the quality of reporting vital statistics data compared to other years. However, sensitivity analysis showed that if a preceding or following year was chosen, the trend lines would be unchanged (e.g. the average annual percent change for 2003-2017 and 2005-2017 was $-0.5 \%, 95 \%$ CI $-0.9 \%$ to $-0.1 \%$, and $-0.7 \%, 95 \%$ CI $-0.9 \%$ to $-0.4 \%$, respectively). Finally, the trends in pulmonary fibrosis mortality may be due to variation in influenza rates by season, rather than reflecting variation in the rate of the true incidence of mortality from pulmonary fibrosis.

Despite the decline in death rates from 2004 to 2017, the positive average annual percent change of overall age-adjusted mortality rates from 1999 to 2017 highlights the ongoing challenges in addressing the burden of pulmonary fibrosis in the USA. 
Evans R. Fernández Pérez

Division of Pulmonary, Critical Care and Sleep Medicine, National Jewish Health, Denver, CO, USA.

Correspondence: Evans R. Fernández Pérez, Division of Pulmonary, Critical Care and Sleep Medicine, Interstitial Lung Disease Program and Autoimmune Lung Center, National Jewish Health; Southside Building, Office \#G12, 1400 Jackson Street, Denver, CO 80206, USA. E-mail: Fernandezevans@njhealth.org

Received: Feb 212019 | Accepted after revision: April 142019

Conflict of interest: E.R. Fernández Pérez reports grants from Boehringer Ingelheim and Genentech, outside the submitted work.

\section{References}

1 Marshall DC, Salciccioli JD, Shea BS, et al. Trends in mortality from idiopathic pulmonary fibrosis in the European Union: an observational study of the WHO mortality database from 2001-2013. Eur Respir J 2018; 51: 1701603.

2 Hutchinson JP, McKeever TM, Fogarty AW, et al. Increasing global mortality from idiopathic pulmonary fibrosis in the twenty-first century. Ann Am Thorac Soc 2014; 11: 1176-1185.

3 Mannino DM, Etzel RA, Parrish RG. Pulmonary fibrosis deaths in the United States, 1979-1991. An analysis of multiple-cause mortality data. Am J Respir Crit Care Med 1996; 153: 1548-1552.

4 Olson AL, Swigris JJ, Lezotte DC, et al. Mortality from pulmonary fibrosis increased in the United States from 1992 to 2003. Am J Respir Crit Care Med 2007; 176: 277-284.

5 Navaratnam V, Fleming KM, West J, et al. The rising incidence of idiopathic pulmonary fibrosis in the U.K. Thorax 2011; 66: 462-467.

6 National Center for Health Statistics. US Department of Health and Human Services, Centers for Disease Control and Prevention. Multiple Cause of Death 1999-2017 on CDC WONDER Online Database (released December 2018). http://wonder.cdc.gov/mcd-icd10.html.

7 Collard HR, Ryerson CJ, Corte TJ, et al. Acute exacerbation of idiopathic pulmonary fibrosis. An international working group report. Am J Respir Crit Care Med 2016; 194: 265-275.

8 Murphy SL, Xu JQ, Kochanek KD, et al. Mortality in the United States, 2017. NCHS Data Brief, no 328. Hyattsville, National Center for Health Statistics, 2018.

9 Kim HJ, Fay MP, Feuer EJ, et al. Permutation tests for joinpoint regression with applications to cancer rates. Stat Med 2000; 19: 335-351.

10 Kostova D, Reed C, Finelli L, et al. Influenza illness and hospitalizations averted by influenza vaccination in the United States, 2005-2011. PLoS One 2013; 8: e66312.

11 Mensah GA, Wei GS, Sorlie PD, et al. Decline in cardiovascular mortality: possible causes and implications. Circ Res 2017; 120: 366-380.

12 Ford ES, Capewell S. Proportion of the decline in cardiovascular mortality disease due to prevention versus treatment: public health versus clinical care. Annu Rev Public Health 2011; 32: 5-22. 